\title{
Is hospitalisation for COPD an opportunity for advance care planning? A qualitative study
}

\author{
*David Seamarka, Susan Blakea , Clare Seamarka, Michael E Hyland ${ }^{b}$, Colin Greavesc, \\ Margaret Pinnucka, David Ward ${ }^{a}$, Adam Hawkins ${ }^{d}$, David Halpine, The East Devon \\ Respiratory Research Group
}

\author{
a The Honiton Research Practice, Honiton, Devon, UK \\ b Department of Health Psychology, University of Plymouth, Plymouth, Devon, UK \\ Department of Primary Care, Peninsula Medical School, Exeter, Devon, UK \\ Area Medical Manager, GSK, Uxbridge, Middlesex, UK \\ e Royal Devon and Exeter Hospital, Exeter, UK
}

Received 22nd October 2011; revised 19th January 2012; accepted 28th February 2012; online 17th May 2012

\begin{abstract}
Background: It is recognised that patients with chronic obstructive pulmonary disease (COPD) should have the chance to discuss endof-life care and advance care planning (ACP). Admission to hospital with an exacerbation may be a possible opportunity.

Aims: To examine whether an admission to hospital for an exacerbation of COPD is an opportunity for ACP and to understand, from the patient perspective, the optimum circumstances for ACP.

Methods: Patients who had a recent admission for an exacerbation of COPD were identified. Sixteen patients and their carers were interviewed. The interviews were analysed using qualitative methodology.

Results: No patients recalled discussions about resuscitation or planning for the future. Hospital admission and discharge was seen as chaotic and lacking in continuity. Some patients welcomed the opportunity to discuss ACP and felt that their general practitioner (GP) would be the best person for this. Others wished to avoid end-of-life care discussions but there was evidence that, with empathetic and knowledgeable support, these discussions could be initiated.

Conclusions: The period of hospitalisation may not be an appropriate time to initiate ACP but may be a milestone that can lead to discussions. GPs should be alert to that opportunity after discharge from hospital.

(C) 2012 Primary Care Respiratory Society UK. All rights reserved.

D Seamark et al. Prim Care Respir J 2012; 21(3): 261-266

http://dx.doi.org/10.4104/pcrj.2012.00032
\end{abstract}

Keywords advance care planning, chronic obstructive pulmonary disease, exacerbation, primary care, qualitative research

See linked editorial by Goemann et al. on pg 241

The full version of this paper, with online appendix,

is available online at www.thepcrj.org

\section{Introduction}

Chronic obstructive pulmonary disease (COPD) is a common chronic disease which causes significant morbidity and mortality. The best available data suggest that there are approximately 900,000 patients diagnosed with COPD in England and Wales' and, allowing for known levels of under-diagnosis, the true number is likely to be around two million. Over 25,000 people died of COPD in the UK in $2007,{ }^{2}$ representing around $5 \%$ of all deaths. Mortality from COPD in the UK is among the worst in Europe, ${ }^{3}$ and audit data from the UK indicate a mortality rate of $13.9 \%$ within 90 days of an admission for an exacerbation. ${ }^{4}$

There is a growing recognition internationally of the need for patients with advanced COPD to receive education about prognosis, end-of-life care and advance care planning (ACP), ${ }^{5.8}$ and such education is a neglected aspect of the management of nonmalignant respiratory disease..$^{9-12}$ The End of Life Care Strategy ${ }^{13}$ for England advocates that all patients with advanced, progressive,

\footnotetext{
* Corresponding author: Dr David Seamark, The Honiton Research Practice, The Surgery, Marlpits Lane, Honiton, Devon EX14 2NY, UK. Tel: +44 (0)1404548544 E-mail: david.seamark@nhs.net
} 
incurable illness should be given the opportunity to participate in $A C P$, and the recent Department of Health Strategy Document for COPD emphasises end-of-life care and structured hospital admission and specialist intervention. ${ }^{14}$ However, the reality is that few such patients participate in ACP.

Clinicians identify numerous barriers to this communication, such as patients being too old or too young, too well or too ill, lack of time and skills, and being unclear whose role it is. ${ }^{15,16}$ Patient barriers reported include the avoidance of difficult issues such as discussions about life and death ${ }^{17}$ and passive acceptance of COPD as part of normal ageing. ${ }^{18}$ A proposed way forward to aid discussions about ACP has been the identification of key transitions in end-of-life care..$^{19,20}$ Such a transition in COPD may be admission to hospital for an exacerbation of COPD. ${ }^{18}$ Patients with COPD are subject to frequent exacerbations of the condition usually due to infection. Although some exacerbations can be managed in the community with adequate clinical and social support, a large number of cases are admitted to acute hospital beds. One in eight $(130,000)$ admissions to hospital in the UK per year are related to COPD, ${ }^{6}$ with around $30 \%$ of patients admitted with COPD for the first time being re-admitted within 3 months. ${ }^{21}$

Admissions to hospital have been seen as missed opportunities for disease prevention. ${ }^{22}$ We wished to examine whether or not an admission to hospital for an exacerbation of COPD was an opportunity to discuss issues concerning resuscitation, ventilation, and ACP. We therefore designed a qualitative study to examine events leading to the admission, recall of discussions about ACP while in hospital, and the views of people with COPD and their carers about the context in which it is appropriate for healthcare professionals to discuss ACP.

\section{Methods}

The study population comprised patients with an admission for an exacerbation of COPD in the previous year to the local District General Hospital (Royal Devon and Exeter Hospital) during 2009. Cases were drawn from two general practices in Devon (a semi-rural practice of 16,500 and a city-based practice of 30,700 patients). Admissions were either identified from discharge data or from cases referred direct to the research team by their general practitioner (GP). Each potential case was reviewed by the GP with exclusion criteria including severe cognitive impairment, non-English speaking, and terminal illness from any cause at the GP's discretion. Patients were invited via a letter signed by their own GP with the offer of an interview to be conducted face-to-face or over the telephone. Patients were free to have a family member or friend participate in the interview. Ethical approval was obtained from the Exeter Research Ethics Committee. The interviews were conducted by an experienced non-clinical qualitative researcher. All interviews took place in the patients' homes.

An interview schedule (see Appendix 1 available online at www.thepcrj.org) was developed following a review of the research, practice, and policy literature and discussion with key informants. These informants included a respiratory physician, a patient with severe COPD and his wife, a professor of palliative care with a specific interest in COPD, a physiotherapist running a pulmonary rehabilitation course, and GP colleagues. The schedule was designed to explore events before, during, and after an admission. Patients were then asked if they were happy to discuss issues concerning death and dying and planning for the future. If in agreement, they were asked whether or not resuscitation (what to do if you stop breathing or your heart stopped), ventilation (helping you with your breathing either using a mask or having a tube down your windpipe), or ACP (planning for the future in case a similar situation occurs) had been discussed during the admission and on their views on the circumstances under which ACP would be discussed.

The audiotapes from each interview were transcribed verbatim and field notes regarding participant interactions were added where appropriate. Each transcript was read by two of the authors (DS and CS) and core themes were identified. These themes were further analysed by DS using a simple qualitative content analysis ${ }^{23}$ and constant comparison methods. ${ }^{24}$ This organised the data into a set of concepts and higher level themes and categories which were then presented to the research group for further refinement.

\section{Results}

In total, 38 patients were invited by letter and 18 agreed to be interviewed. Sixteen patients (12 men and four women) aged 58-90 years were interviewed; three had mild disease, six had moderate disease, six had severe disease and one had very severe disease. Two men with severe disease who had agreed to take part died before their interview could take place. One participant was a non-smoker, one a current smoker, and 14 were ex-smokers (Table 1).

Seven patients (four men and three women) aged 53-85 years declined by letter. Two had moderate disease, two had severe disease, and in three cases the severity of disease was not known. Four of these patients were ex-smokers and three current smokers. Two of these patients also died before the end of the study.

\begin{tabular}{llllll} 
Table 1. Patient details & & \\
Age & Gender & \multicolumn{2}{l}{$\begin{array}{l}\text { Smoking Pack } \\
\text { status }\end{array}$} & $\begin{array}{l}\text { Year of } \\
\text { years }\end{array}$ & $\begin{array}{l}\text { Severity } \\
\text { diagnosis }\end{array}$ \\
\hline 61 & Male & Ex & 30 & 1995 & Severe \\
\hline 79 & Male & Ex & 50 & 2000 & Severe \\
\hline 87 & Male & Ex & 45 & 2008 & Severe \\
\hline 80 & Male & Ex & Pipe & 1999 & Severe \\
\hline 79 & Male & Ex & $5 / 6$ & 2003 & Moderate \\
\hline 58 & Male & Ex & 5 & 2008 & Severe \\
\hline 69 & Female & Ex & 22 & 2005 & Moderate \\
\hline 83 & Male & Ex & $30+$ & 1999 & Moderate \\
\hline 90 & Male & Ex & 12 & 2004 & Moderate \\
\hline 65 & Male & Current & 70 & 2006 & Severe \\
\hline 78 & Male & Ex & 45 & 2010 & Mild \\
\hline 62 & Female & Ex & 80 & 2009 & Mild \\
\hline 62 & Female & Ex & 43 & 2007 & Moderate \\
\hline 72 & Male & Ex & 63 & 2004 & Very severe \\
\hline 82 & Female & Non & n/a & 2005 & Moderate \\
\hline 76 & Male & Ex & 37 & 2010 & Mild \\
\hline
\end{tabular}

One pack year=one pack (20 cigarettes) per day for one year COPD severity (ATS/ERS, 2004): mild FEV $1=\geq 80 \%$ predicted; moderate $\mathrm{FEV}_{1}=50-79 \%$ predicted; severe $\mathrm{FEV}_{1}=30-49 \%$ predicted; very severe $\mathrm{FEV}_{1}=<30 \%$ predicted. 
Four of the participants were interviewed in the presence of their spouse and full-time carer and one with their daughter who was their part-time carer. For eight it was their first admission with an exacerbation of COPD and the other eight had had at least one previous admission.

No reply to the invitation was received from 13 patients. No further attempt to contact them was made and their details were not sought.

\section{Was ACP discussed in hospital?}

No patients recalled discussion in hospital about issues of resuscitation, the possibility of being ventilated, and planning for future exacerbations. One patient had a directive kept at home asking not to be resuscitated. This was composed with the help of a community matron; however, the form did not accompany the patient to the hospital.

It's in the yellow book, there's a form in there for that purpose, no resuscitation ... that's supposed to go with the person ... but not very often do they (the hospital doctors) ask for it. [Patient 14]

Possible reasons for lack of discussion about ACP emerged in the following theme.

\section{Hospital admission and discharge: chaotic and too ill to engage}

The majority of patients (14 of 16) were admitted as emergencies by ambulance. The process of admission was recalled as being hurried with a minimum of discussion with the ambulance crew or attending GP.

I was seen by a doctor as far as I can remember and pushed into hospital. [Patient 8]

No chance to think, I was whipped in and that was it "you're going". [Patient 3]

We were whizzed straight into the Medical Emergency or surgical place ... I couldn't tell you. [Patient 3]

The actual inpatient stay was seen as chaotic by most patients with a lack of recall about where care took place and by whom. This was compounded by patients being extremely ill, some experienced hallucinations, and many had no recall of the events of the first few days of the admission.
On reflection, patients felt that the admission had benefited them by providing reassurance and the relief of anxiety. Plans for discharge were another variable feature of the admission with some patients receiving follow-up instructions and others seemingly offered no specific follow-up (see Box 1).

\section{Attitudes to advance care planning}

All patients agreed to discuss ACP and related issues such as resuscitation, ventilation, and planning for future exacerbations. For many patients the emotional impact of discussing such concepts was too difficult and led to avoidance of decisions.

It's a subject I would prefer not to have to think about greatly. [Patient 10]

For some, ACP was clearly a new concept and on reflection was seen as important and discussions moved to a more problemfocused basis.

It's going to make me think ... it's something I wouldn't have

thought of. Interesting subject. [Patient 9]

It was also viewed as a difficult topic about which it might be hard to make concrete decisions. In terms of resuscitation, the view was frequently expressed that only if a successful outcome could be guaranteed would they consider the option. This position led to the idea of resuscitation being a medical decision to be made by clinicians.

Others found the issues concerning resuscitation, ventilation, and future episodes of illness difficult to discuss with the attitude that, if 'it' (cardiopulmonary arrest) occurs, then "let's hope it's quick". Joint interviews revealed different agendas between patient and spouse at times, especially regarding the future course of the illness and managing further exacerbations (see Box 2).

\section{Who to talk to - someone you know or someone who knows?}

In answer to the question who should discuss ACP, there was a desire for someone they know and who knew them. Someone with a good knowledge of the condition was also desirable. This usually translated to that person being their GP. Some patients envisaged a discussion with their family being present to help the decision process (see Box 3).

Box 1. Hospital admission and discharge

\section{Chaotic admission}

Well they put you in, they boot you and then you wait until somebody comes and assesses you. It takes some time sometimes. I've been there twice. [Patient 1]

it was as though it was the blind following the blind. Yes because (Consultant) is the bowel and gastro bloke and I couldn't understand how the hell I'd ended up on his ward when it was supposed to be for my breathing. [Patient 4]

\section{Recall affected by serious illness}

But the breathing was scary because there's no breath there, because it's hard to explain ... It's like I was suffocating, a horrible feeling. And I was getting confused, I remember getting confused, but I'm confused in any case (laughs). But all joking aside it was very scary. [Patient 13]

Well they assess you and they take you on the ward and then they do all the necessary, you know. I can't actually remember what they did to be honest. But they did their job. [Patient 1]

Bearing in mind I was unaware of all of this ... this happened on every occasion I went in, I just go ... I'm hallucinating ... the next thing I know is that four days later I wake up in hospital. [Patient 14]

\section{Reassurance provided by admission}

At the time I was quite thankful, because I really was quite scared because I'd never really experienced anything quite like that before, you know, and I really was quite relieved that they were going to do something because it was quite frightening because you feel as though you couldn't breathe and cough. I've never had such a deep cough. [Patient 6]

\section{Follow-up arrangements}

Oh yes, to go back to see the respiratory nurse, which I've been back, three times now I think, six weeks after I came home then she didn't want to see me for 6 months and then I went a fortnight ago, a week ago. She just takes your oxygen levels and blow into the thing and that. [Patient 6]

No not with that one, no. None whatsoever. Except obviously I went to my own doctor, he had a report on it. [Patient 12]

Yes, yes, I did, that was from my own doctor. In fact the doctor said if you really get desperate again, well you'll just have to call the ambulance again. [Patient 7] 


\section{Box 2. Attitudes to ACP}

\section{Avoidance of decisions}

Have you ever thought about those kind of things yourself?

Well no, not really, because I don't think about dying. If I was one of these morbid people who went about thinking well I'm going to die, then perhaps I would think about it, but it doesn't enter my head. [Patient 10]

Well, to be honest, I wouldn't necessarily want to discuss it because I feel like it's tempting fate, but it's a subject I would prefer not to have to think about greatly, you know. Well, the more you think about it perhaps it becomes difficult, but if you don't think about it it's not difficult. As I say, it's nothing I've ever thought about and, if I do, well I probably think well if it does happen one day, let's hope it's quick. [Patient 10]

If they happen (these things), they happen, if they don't they don't and that's life that's life. Don't worry dear (to wife who has expressed concern that he does not want to discuss these issues). [Patient 3]

To be honest with you, no, not really no. I mean it's the sort of thing you think, well it's not going to happen to me, but it probably could quite easily I suppose couldn't it? I never really thought about it to be honest to you. [Patient 6]

\section{A difficult but worthwhile concept}

Do you think these things should be talked about?

I think they should yeah ... I'm 66 in January. So sometimes that makes me weigh up the question, well I am going to, is the breathing going to kill me or am I going to pass away in my sleep quite peacefully, you know. Do I go for resuscitation or don't I go for resuscitation, so it's a lot of things to weigh up. [Patient 11]

It wasn't discussed and I would have liked to have known more about resuscitation and the ventilation side of it so that I could understand what it was all about. [Patient 14]

A consultant or specialist nurse was seen as someone with the clinical knowledge but not necessarily the personal relationship. One person suggested a group setting might be a useful forum.

A discussion group with (consultant) and the respiratory staff there so that they could put things over and not hold anything back. [Patient 11, page 10]

\section{Discussion}

\section{Main findings}

From the descriptions of the hospital admission it is clear that most patients saw this as chaotic, bewildering, and lacking in continuity. In addition, being extremely ill made decision-making and recall of events very difficult. In the light of these findings, it was perhaps not surprising that none of the patients recalled issues about end-of-life care and their personal wishes being discussed with hospital staff during their admission.

The arrangement of suitable follow-up, either in primary or secondary care, varied from being haphazard to reasonably planned but, again, none of the subjects recalled discussions about end-oflife care resulting as a consequence of the admission. When asked directly by the interviewer, all participants were willing to talk about end-of-life issues such as resuscitation, ventilation, and what the future might hold. Responses to whether or not such things should be discussed fell into two broad categories. There were those patients who revealed an emotion-focused style of coping with the concept of death, where negative emotions were avoided by avoidance of the topic. Other participants, who adopted a more
Ummh, well yes they should be discussed, I mean it doesn't matter what age you are, it could happen to anybody at any time. [Patient 10]

So do you think these kind of issues are generally difficult, or just for you really?

I think they might be difficult for a lot of people, because I think that the strongest people, emotions are when you are talking about yourself. [Patient 9]

Not that easy to talk about?

No, but I think I'd want it addressed, yeah, I think that it's very important, yeah because I would have to come to terms with that anyway, about what the person, whether it would be the GP or the consultant, was saying to me. So it, I wouldn't want not to be, to have it discussed with me. I think that's really important it's like if you said to me 'well I'm not going to tell you' but you've got six months to live, actually I'd want to know, even though emotionally, I'd be angry with the whole world and probably very upset, that I think most people would feel. Not all perhaps because we're all different. [Patient 9]

\section{Resuscitation: a medical decision?}

So do you mean that you are prepared to take things as they come when your time comes?

that's right, that's right. I would always look at it to say if you think it's worth the effort, if you think it's worth doing something then do it, but otherwise don't bother. Whether they (the doctors) think it would be successful. [Patient 12]

I've always had the view that they (doctors) know best, and that's it ... If they thought it was for the best, then let them get on with it. [Patient 16]

problem-focused style, felt such conversations should occur and were a welcome opportunity for them and their families to deal with difficult decisions..$^{25}$ There was evidence that some patients - after an initial emotion-focused response - would welcome a more problemfocused style if supported by an empathetic health professional.

Most patients favoured their own GP as the person best placed to talk to them about end-of-life issues. Substantial value was placed on knowing the doctor, being known by them, and a relationship built on trust. The setting of such discussion varied, with most favouring the home or GP surgery in the period after admission. For some, a person with authority and a good knowledge base (consultant or specialist nurse) would also be a suitable person with whom to discuss such matters. Family involvement in such discussion was seen as beneficial by some participants.

The desire for resuscitation only to be attempted if a good outcome could be guaranteed, with a sense of giving responsibility over to the clinicians involved, was expressed a number of times.

\section{Strengths and limitations of this study}

This study was based on admissions to a single average-sized teaching hospital with well organised respiratory medicine services and outpatient care. It is likely that these findings would be reflected in other hospitals in the UK. None of the participants was from an ethnic minority, although the cohort did represent a varied demographic group. Patients were recruited from two practices that operated personal lists of patients and hence provided continuity of primary care. Patient experience may be different in practices with pooled lists where a patient may not have an identified usual GP. The number of participants and response rate was appropriate for a 


\section{Box 3. Who to talk to about ACP}

\section{Someone you know and who knows you}

Your own GP, they seem to know what's going on, you know, they've got their computer there and they follow it up don't they, which they should do I suppose. But I mean, we are their concern you know, they are our doctor, that's it. It's more personalised isn't it, with your own doctor, and that's the way I like it ... because a consultant you only see every now and then, very few and far between, but your doctor is on call if you need them and when you do see them you can talk directly face to face. [Patient 1]

Umm, No because I know my doctor and I'm not saying I don't trust (hospital staff), but I do trust my doctor and he's be the one that I'd go to first of all. [Patient 13]

\section{Someone who knows}

Well it's got to be a doctor hasn't it? At the end of the day it's only doctor (consultant) who can actually spell all that out to you, nobody else can. [Patient 2]

qualitative study of this nature and saturation of data was achieved. This was when analysis of new transcripts did not produce any new themes or categories and the content confirmed the findings from previous transcripts.

At the time of the study, patients were unlikely to have had contact with a community matron.

The purpose of this study was not to check the accuracy of recall but whether it was recalled at all, and therefore if it was an appropriate time for such discussions. The group considered triangulation by review of the hospital notes, but personal experience $(\mathrm{DH})$ indicated that many of the discussions about ceilings of treatment and decisions regarding acute resuscitation are made soon after admission and hence, although it is likely that a resuscitation status would be documented, it would not be a reliable source of knowing what had been discussed.

\section{Interpretation of findings in relation to previously published work}

ACP has been shown to produce benefits to patients and carers, ${ }^{26}$ yet the implementation of ACP is difficult. The barriers identified by clinicians have been well documented ${ }^{15,17,27}$ and may be overcome with training and education. ${ }^{26,28}$ More recently, patient factors have been identified, with a Dutch study showing that patients with endstage COPD considered their limitations as normal and did not realise there was anything that could improve their situation. ${ }^{29}$ Pinnock and colleagues found that patients with severe COPD accept COPD as a way of life rather than an illness, and that policy focus on identifying a time point for transition to palliative care has little resonance for people with COPD or their clinicians. ${ }^{18}$ With the difficulty of identifying a definite transition point to palliative care in the COPD illness trajectory, the concept of key milestones along a lifetime journey with COPD has developed. 19,20 Thresholds at which ACP might be discussed have been described and include forced expiratory volume in $1 \mathrm{~s}\left(\mathrm{FEV}_{1}\right)$ less than $30 \%$ predicted, oxygen dependence, and hospital admission for exacerbation of COPD. ${ }^{30}$

This study aimed to discover whether or not an admission to hospital for an exacerbation of COPD was an opportunity for initiation of discussion about ACP. It appears from the chaotic nature of the admission and the severity of the illness that this is not necessarily an appropriate time. However, the other aim of the study was to see if an admission was a potential trigger to starting such
I think it ought to be the specialist nurse, somebody who is reasonably competent and, shall we say, fully acquainted and knowledgeable about COPD. [Patient 8] Anybody who's got a qualification to do it, no particular person. [Patient 3]

\section{Family support}

Yes, Yeah and the other thing is, it wouldn't just be my GP, it would be my children. That would be very important to me, that the three children understood, understood my wishes and why. [Patient 9]

At home I would have thought, apart from the doctor, my doctor. And I'd like one of my daughters to be with me because my husband's a bit deaf. [Patient 13]

So what you'd like is a discussion with your doctor with another member of the family present?

Yes. It's strange, I've not thought of this like you say now. [Patient 13]

discussions after discharge, and this seemed to show promise. Ambivalent patient responses to end-of-life discussions have previously been observed in the UK and USA. ${ }^{17,31}$ Here, interviews with severely affected COPD patients after a hospital admission for exacerbation indicated that patients' information needs were diverse and sometimes ambiguous and contradictory. Many patients appeared to be 'in denial' regarding the life-threatening effect of their illness. A more positive outcome was observed in a communitybased study of patients with stable COPD which revealed that discussions about artificial ventilation and cardiopulmonary resuscitation could be conducted without causing distress. The attitudes to resuscitation could not be predicted from parameters of respiratory disease severity or age. ${ }^{32}$

Previous work has indicated that the optimal context for end-oflife discussions was within a caring, trusting, long-term relationship which offered open and repeated negotiations for patients' preferences for information, ${ }^{33}$ with the family physician being well placed for providing such care. ${ }^{34}$

Our study group indicated a willingness to talk about ACP, and that having a relationship of trust with a clinician and the clinician having a good clinical knowledge of the subject could help move the patient from a position of emotional avoidance to that of being more problem-focused. Variations between patients suggest that interventions should be sensitive to the different ways in which people cope with emotional upset and that an incremental approach to such interventions should be adopted. ${ }^{35}$ Evidence from psychological reviews of health campaigns suggests that people respond to threatening situations with denial and/or avoidance, and may respond better if there is also a message of hope and that something can be done about the situation. ${ }^{36}$

\section{Implications for future research, policy and practice}

This research has highlighted the perceived chaotic nature of some emergency admissions for patients with serious respiratory illness. Although some of this may be due to the nature of the illness, it is possible that the organisation of the admission could be improved to facilitate patient care. Whether or not such an admission to hospital is a milestone that might open up opportunities for discussion about ACP needs to be explored. Further research is needed to establish what patients really want from ACP and the most appropriate time for discussions. Further investigation is needed to determine which 
healthcare professionals should be involved and the support required to facilitate this in daily practice.

\section{Conclusions}

Admission to hospital for an exacerbation of COPD was recalled as a chaotic experience by most patients in the study. After the admission the patients expressed an openness to discussions about ACP. However, the admission itself may not be the most appropriate time for this. The preferred person with whom to have the discussions was an informed and empathetic health professional. GPs often provide the relational continuity that patients value and are well placed to engage in such discussion.

\section{Handling editor Dianne Goeman}

Acknowledgements We would like to thank all the patients who took part in this study for their participation and interest in the subject. We also thank the GPs and research staff at the two practices (Honiton and St Thomas) for their help with identifying and recruiting patients.

Conflicts of interest AH is employed as Area Medical Advisor for GSK (UK), Uxbridge, Middlesex and Honorary Clinical Assistant at RUH, Bath. None of the other authors have any competing interest for this paper.

Contributorship All authors are part of the East Devon Respiratory Research Group. The group conceived the idea for the research and worked together on planning the research protocols, interview schedule and analysis and discussion of the analysis. The group met to discuss the findings and work on the paper. Drafts of the paper were prepared by DS and CS and presented to other members of the group who contributed to revisions of the paper. DS leads the research group. He read all the interviews, started the thematic analysis and wrote the first draft of the paper. SB undertook all the interviews and transcriptions and worked on the analysis. CS read the transcripts, worked on the thematic analysis with DS and SB, and worked on the paper with DS. MH contributed particularly on the psychological basis of some of the findings. CG contributed particularly to the qualitative analysis. MP provided a nursing perspective to the condition and patient experience and contributed to the group. DW helped with contributing ideas to the research protocol and with the paper. AH contributed to the discussion of the findings and revisions of the paper. DH provided an interface with the hospital setting and particularly contributed to revisions of the paper and background to the condition and hospital treatments. DS is the guarantor of the paper.

Funding This project was funded by a grant from the Royal Devon and Exeter NHS Foundation Trust Research and Development Directorate.

Ethical approval Ethical approval was obtained from Exeter Local Research Ethics Committee REC ref 10/H0202/2.

\section{References}

1. Healthcare Commission. Clearing the air. A national study of COPD. London: Commission for Healthcare Audit and Inspection, 2006.

2. National Statistics. Health statistics quarterly 34 (online supplement). London: The Stationery Office, 2007.

3. Halpin DMG. Improving the management of COPD. BMJ 2011;342:d1674.

4. Roberts CM, Stone RA, Buckingham RJ, Pursey NA, Lowe D. Acidosis, non-invasive ventilation and mortality in hospitalised COPD exacerbations. Thorax 2011;66:43-8. http://dx.doi.org/10.1136/thx.2010.153114

5. National Institute for Health and Clinical Excellence (NICE). COPD: management of COPD in primary and secondary care. Thorax 2004;59 (Suppl 1):1-232.

6. Department of Health. The National Services Framework for long term conditions. London: Department of Health, 2005.

7. O'Donnell DE, Aaron S, Bourbeau J, et al. Canadian Thoracic Society recommendation for management of chronic obstructive pulmonary disease: 2007 update. Can Respir J 2007;14 (SupplB):5-32B

8. Lanken PN, Terry PB, DeLisser HM, et al. An official American Thoracic Society clinical policy statement: Palliative care for patients with respiratory diseases and critical illnesses. Am J Respir Crit Care Med 2008;177:912-27. http://dx.doi.org/10.1164/rccm.200605-587ST

9. Curtis RJ, Engelberg R, Wenrich M. Communication about palliative care for patients with COPD. J Palliat Care 2005;21:157-64.

10. Curtis RJ. Palliative and end-of-life care for patients with severe COPD. Eur Respir J 2007;32:796-803. http://dx.doi.org/10.1183/09031936.00126107
11. Gardiner C, Gott M, Small N, et al. Living with advanced chronic pulmonary obstructive disease: patients concerns regarding death and dying. Palliat Med 2009;23:691-7. http://dx.doi.org/10.1177/0269216309107003

12. Gardiner C, Gott M, Payne S, et al. Exploring the care needs of patients with advanced COPD: an overview of the literature. Respir Med 2010;104:159-65. http://dx.doi.org/10.1016/j.rmed.2009.09.007

13. Department of Health. End of Life care strategy: promoting high quality care for all adults at the end of life. London: Department of Health, 2008.

14. Department of Health. An outcomes strategy for people with chronic obstructive pulmonary disease (COPD) and asthma in England. London: Department of Health, 2011: p.39. http://www.dh.gov.uk/en/Publicationsandstatistics/Publications/ PublicationsPolicyAndGuidance/DH_127974.

15. Gott M, Gardiner C, Small N, et al. Barriers to advance care planning in chronic obstructive pulmonary disease. Palliat Med 2009;23:642-8. http://dx.doi.org/ 10.1177/0269216309106790

16. Spence $A$, Hasson $F$, Waldron $M$, et al. Professionals delivering palliative care to people with COPD: qualitative study. Palliat Med 2009;23:126-31. http://dx.doi.org/10.1177/0269216308098804

17. Knauft E, Nielsen RA, Curtis JR, et al. Barriers and facilitators to end-of-life communication for patients with COPD. Chest 2005;127:2188-96 http://dx.doi.org/10.1378/chest.127.6.2188

18. Pinnock $H$, Kendall $M$, Murray SA, et al. Living and dying with severe chronic obstructive pulmonary disease: multi-perspective longitudinal qualitative study. $B M J$ 2011;342:d142. http://dx.doi.org/10.1136/bmj.d142

19. Boyd K, Murray SA. Recognising and managing key transitions in end of life care. BMJ 2011;341:c4863. http://dx.doi.org/10.1136/bmj.c4863

20. Thorns A, Cawley D. Palliative care in people with chronic obstructive pulmonary disease. BMJ 2011;342:d106. http://dx.doi.org/10.1136/bmj.d106

21. British Thoracic Society. The burden of lung disease. 2nd edition. London: British Thoracic Society, 2006. http://www.brit-thoracic.org.uk/Portals/0/Library/BTS\%20 Publications/burdeon_of_lung_disease2007.pdf.

22. Brull R, Ghali WA, Quan H. Missed opportunities for prevention in general internal medicine. CMAJ 1999;160:1137-40.

23. Bryman J. Social research methods. Oxford: Oxford University Press, 2001.

24. Glaser BG, Strauss AL. The discovery of grounded theory: strategies for qualitative research. New York: Aldine, 1967.

25. Lazarus RS. Coping theory and research: past, present and future. Psychol Med 1993:55:234-7

26. Detering $K M$, Hancock $A D$, Reade $M C$, Silvester $W$. The impact of advance care planning on end of life care in elderly patients: randomised controlled trial. $B M$ 2010;340:c1345. http://dx.doi.org/10.1136/bmj.c1345

27. Elkington $H$, White $P$, Higgs $R$, Pettinari CJ. GPs' views of discussions of prognosis in severe COPD. Fam Pract 2001;18:440-4. http://dx.doi.org/10.1093/fampra/18.4.440

28. Barnes S, Gardiner C, Gott M, et al. Patient-professional communication interventions in life-limiting illness: A review. Journal of Pain and Symptom Management (in press).

29. Habraken JM, Pols J, Bindels PJE, Willems DL. The silence of patients with end-stage COPD: a qualitative study. Br J Gen Pract 2008;58:844-9. http://dx.doi.org/10.3399/bjgp08X376186

30. Patel K, Janssen DJ, Curtis JR. Advance care planning in COPD. Respirology 2012;17:72-8. http://dx.doi.org/10.1111/j.1440-1843.2011.02087.x

31. Gore JM, Brophy CJ, Greenstone MA. How well do we care for patients with end stage chronic obstructive pulmonary disease (COPD)? A comparison of palliative care and quality of life in COPD and lung cancer. Thorax 2000;55:1000-06. http://dx.doi.org/10.1136/thorax.55.12.1000

32. Gaber KA, Barnett M, Planchant $Y$, McGavin CR. Attitudes of 100 patients with chronic obstructive pulmonary disease to artificial ventilation and cardiopulmonary resuscitation. Palliat Med 2004:18:626-9

http://dx.doi.org/10.1191/0269216304pm944oa

33. Clayton JM, Butow PN, Tattersall MHN. When and how to initiate discussion about end-of-life issues with terminally patients. J Pain Symptom Manage 2005;30:132-44. http://dx.doi.org/10.1016/j.jpainsymman.2005.02.014

34. Dean MM. End-of-life care for COPD patients. Prim Care Respir J 2008;17:46-50. http://dx.doi.org/10.3132/pcri.2008.00007

35. Barclay S, Maher J. Having difficult conversations about the end of life. BMJ 2010;341:c4862. http://dx.doi.org/10.1136/bmj.c4862

36. Witte K, Allen M. A meta-analysis of fear appeals: implications for effective public health campaigns. Health Educ Behav 2000;27:591-615.

http://dx.doi.org/10.1177/109019810002700506 
Appendix 1: Interview Schedule

\section{Events surrounding latest admission to hospital and whether end-of-life issues were discussed.}

Pre-admission

1. What happened before the decision was made to go to hospital?

Prompts:

- What led you to decide to go into hospital: who made the decision?

- What were you expecting from the consultation before admission?

- What were your symptoms?

- What was different on this occasion?

- Who took the initiative?

- Context, time of day, day of week

- Expectation of hospital (hi-tech, place of safety, previous experience of admission)

\section{Admission/discharge}

\section{When you arrived in hospital, what happened?}

Prompts:

- What was the first place of assessment/treatment?

- Where were you looked after?

- Were you put on a ventilator/non-invasive positive ventilation (NIPPV)/oxygen mask?

\section{What happened on discharge and how was it managed?}

Prompts:

- $\quad$ Follow-up arrangements (GP, respiratory nurse, medical outpatients)

- Any information about future exacerbations

4. Are you happy to talk about managing issues about further exacerbations? If yes, are you also happy to discuss issues concerning resuscitation, ventilation, and advance care planning?

Have you ever been resuscitated (CPR) or ventilated before? By this we mean:

Resuscitation: what to do if you stopped breathing or your heart stopped.

Ventilation: helping you with your breathing either using a mask or having a tube down your windpipe.

Advance care planning: planning for the future in case a similar situation arises.

Prompts:

- Has anyone discussed these issues with you, either before or after recent admission?

- Have you ever thought about these issues?

- Has this last admission changed your views?

- Who do you think should be discussing such issues with you? Specialist Nurse/GP?

- Where and when should these issues be discussed? In hospital before discharge? After discharge at the surgery? 